\title{
Promoting Service Learning in Higher Education in Vietnam
}

\author{
Hue Thi Thanh Tran ${ }^{1}$ \\ ${ }^{1}$ Faculty of Foreign Languages, AnGiang University, \\ Vietnam National University, \\ Ho Chi Minh City, Vietnam
}

\begin{abstract}
Service learning is a pedagogical approach that incorporates course content, meaningful service, and critical reflection to deepen student learning, personal growth, and citizenship. Through service learning students apply their learning in real-life settings, develop necessary skills, help to resolve community problems, and support social changes. In higher education, service learning is suggested as a powerful strategy to promote a cooperation of key institutional missions including teaching, research, and services. However, despite its positive impacts in education and popularity in many parts of the world, service learning has not been systematically implemented and widely studied in Higher Education in Vietnam. This paper reviews the concept of service learning to provide a more comprehensive understanding of this pedagogy and its impacts on students and related stakeholders. The paper then suggests implications for promoting service learning in Higher Education in Vietnam.
\end{abstract}

Keywords:service learning, Higher Education, community engagement, Vietnam

\section{Introduction}

Higher education (HE) missions in the world in general and in Vietnam in particular are associated with striving for excellence in teaching, research, and services. Service learning (SL) is considered as a powerful pedagogy to support a cooperation of these key missions in HE (Bringle \& Hatcher, 1996, 2000). Previous studies show that SL experiences create positive outcomes for students in various areas such as academic, personal, social, and citizenship development (Battistoni, 2002; Bringle \& Hatcher, 1996; Celio et al., 2011; Conway et al., 2009; Deeley, 2010).

Scholars have called for more focus on employing SL in HE due to its documented impacts on student outcomes, and opportunities to strengthen partnerships between higher educational institutions
(HEIs) and communities (Battistoni, 2002; Bringle \& Hatcher, 2000; Conway et al., 2009). Service learning is considered as a powerful pedagogy and has been widespread in HE in the United States and many other countries such as Canada, Spain, Hong Kong, the Philippines, etc. (Caspersz \& Olaru, 2015; Celio et al., 2011; Gil-Gómez et al., 2015). However, the practices and impacts of SL have not been widely studied in HE in Vietnam. This paper, therefore, reviews literature on SL to offer a more comprehensive understanding about SL in HE. The paper then suggests implications for promoting SL in $\mathrm{HE}$ in Vietnam.

\section{Service Learning}

Service learning is defined in different ways, and there are other terms to refer to SL such as civic engagement (Battistoni, 2003), community-based learning, a methodology (Bringle \& Hatcher, 1996), an educational approach (Creus et al 2019), a pedagogy, an instructional method, or a powerful learning tool (Deeley, 2010).

In general, SL is conceptualized as a form of experiential learning that combines academic coursework with meaningful service activities in the community (Bringle \& Hatcher, 1996). Within an educational program or at a curriculum level, SL is defined as a pedagogical approach that integrates community service in the academic curriculum (Creus et al., 2019). Specifically, SL is "a creditbearing educational experience in which students participate in an organized service activity in such a way as to gain further understanding of course content, a broader appreciation of the discipline, and an enhanced sense of civic responsibility" (Bringle \& Hatcher, 1996, p. 222). Through SL, students engage in organized volunteer work that will enhance their learning and contribute to the communities (Warren \& Sellnow, 2021). 
Service learning is designed as a component of the course content and is organized to support clear learning objectives (Bringle \& Hatcher, 1996). It is important that the service is connected with the coursework, and through critical reflections, students make sense of their service experiences to deepen their understanding of abstract concepts in formal learning (Deeley, 2010).

The most crucial component is critical reflection (Caspersz \& Olaru, 2015; Deeley, 2010)which enables students to connect academic coursework to their SL experiences in the community or placement. Critical reflection promotes "different levels and complexities of critical thinking" in students" learning process (Deeley, 2010, p. 47). Since SL integrates academic objectives with real-life projects that students undertake with community members, it involves mutual learning and collaborations between students and other stakeholders. Students, course instructors, and community partners are key stakeholders in planning, implementing, and evaluating SL activities (Caspersz \& Olaru, 2015).

Service learning is distinguished from other kinds of experiential learning activities which are regularly organized within or outside the campus such as internships, field work, volunteer work, or extracurricular activities (Bringle \& Hatcher, 1996). These activities mainly focus on either learning or service goals. For example, volunteer work focuses mainly on the service and its recipients. Fieldwork and internships are primarily skill-based and aim to develop student professional skills. Service learning, unlike these activities, is a course-based activity that links coursework to meaningful service, and targets both learning and service goals. Through participating in SL, students improve knowledge and professional skills and develop civic responsibility while engaging in the service to address community needs (Bringle \& Hatcher, 1996).

\section{Positive Impacts of Service Learning}

\subsection{Benefits to Students}

The benefits of SL participation to student outcomes have been well documented in the literature. For example, a meta-analysis of 103 studies found that SL had positive effects on four outcomes including academic, personal, social, and citizenship outcomes (Conway et al., 2009). These were specified as follows: (1) academic outcomes include cognitive and academic changes, and motivation to learn; (2) personal outcomes are related to students' thoughts and feeling about themselves, their motives, values, and well-being; (3) social outcomes deal with students' relationships to others and beliefs about others, and (4) citizenship outcomes include personally responsible, participatory, and justiceoriented citizenship. Among these, largest changes

\section{ISSN 2455-6378}

were noted for academic and social outcomes gained by the students who participated in SL.

Similarly, Celio, Durlack\&Dymnicki's(2011) metaanalysis of $62 \mathrm{SL}$ studies provided evidence that SL had positive impacts on students' attitudes, social behaviors, and academic achievement. Particularly, students experienced positive changes in 5 outcome areas: attitudes toward self, attitude toward school and learning, civic engagement, social skills, and academic performances.

Other studies explored impacts of SL from students' perspectives. For instance, Deeley(2010) studied effects of SL on students' learning through a SL course in a Public Policy curriculum for undergraduates in the Department of Urban Studies at the University of Glasgow, Scotland. This qualitative study employed two focus groups conducted before and after the SL course and 12 semi-structured in-depth interviews with the students. Findings showed that students reported positive effects of SL on their intellectual and personal development. Through engaging in SL, students developed intellectual skills, had deeper learning, connected theory to practice, and experienced personal transformation. For the students, SL created "life-changing effects" (Deeley, 2010, p. 49).

Similarly, Caspersz and Olaru's research (2015) showed that students highly valued their SL experiences and reported that SL improved their abilities to apply formal learning to solve community problems, and citizenship skills. The students also perceived SL as "transformative learning" (p.2), i.e. learning that fosters different ways of thinking about the current situation and about their previous beliefs, and thus transforms the students themselves. Moreover, through SL experiences, students learned how to create social changes (Caspersz \& Olaru, 2015).

In the field of teacher education, there is evidence that SL improves academic outcomes, practical skills, career readiness, and professional identity of pre-service teachers (Carrington et al., 2015; GilGómez et al., 2015). Specifically, Gil-Gómez's qualitative research (2015) explored how SL created changes in pre-service teachers of physical education in Spain. The study found that pre-service teachers who engaged in SL experienced significant development in academic and personal learning. They reported increasing cultural understanding and empathy with the community members they served, i.e. children with disabilities. Service learning participation also developed students' professional identity which was important for their teaching career (Gil-Gómez et al., 2015). Other studies also noted that SL participation facilitated transformative learning, and improved pre-service teachers' attitudes and values which were necessary for the teaching profession (Carrington et al., 2015; Hildenbrand \& Schultz, 2015). 
In general, previous studies across different contexts shared evidence about positive effects of SL on students' outcomes. Additionally, research shows long-term impacts of SL on perspectives, skills, and actions of students after college (Fullerton et al., 2015).

\subsection{Benefits to Instructors}

Literature also notes several benefits of SL to instructors or academics. Courses with SL components have potential to enable academics or instructors to fulfill three main duties in HE: teaching, research, and services (Darby \& Newman, 2014). In fact, as a teaching and learning approach, SL expands course objectives to include meaningful service and civic education, and makes teaching more innovative and enjoyable. The implementation of SL also enables instructors to accommodate different learning styles and diversity of the students, as well as enhances teaching quality and students' satisfaction of courses (Bringle\& Hatcher, 1996).

In SL, instructors employ different methods for assessing student learning. For example, students' service-related products and activities such as case studies, journals, portfolios, self-assessment, teambased learning, or assessment from organizations, etc. can be collected and evaluated. Therefore, teaching and learning become more collaborative, reflective and authentic.

Service learning can also enhance academics' professional development and opportunities for research. In SL, instructors need to work with community partners to analyze community needs, design SL component of their courses, and engage in the process of implementing, managing, and evaluating students' learning through the service. This cooperation and partnership promote mutual learning and opportunities for research.

\subsection{Benefits to Universities and Communities}

Impacts of SL expand to universities and communities. SL supports university missions and visions related to service engagement (Bringle \& Hatcher, 1996, 2000). Through offering SL programs, HEIs can expand partnerships with communities (Hildenbrand \& Schultz, 2015). Service learning can support HEIs in achieving their overall objectives of promoting a well-rounded development of students. HEIs that provide SL for students reported increased student retention and satisfaction with the institutions (Bringle \& Hatcher, 1996, 2000).

Service learning also benefits communities as it enables the community to receive necessary services, resources and assistance in resolving practical problems. In a study by Hildenbrand (2015), community partners reported satisfaction with the
ISSN 2455-6378

quality of student service, and commented that the SL met their organization's needs. However, the impacts of SL on communities have not been clearly stated due to limited research on this area in the literature.

\section{Barriers to Service Learning}

Besides emphasizing SL benefits, some researchers note barriers related to SL practices, and challenge the perception that SL is always beneficial. For example, Deeley(2010) found that a common barrier to SL was students' resistance or poor preparation for SL. This barrier may be resulted from student inability to make connection between their SL experiences and learning, which may lead to frustration, misunderstanding, and feeling of uncertainly when stepping out of their comfort zone (Deeley, 2010). The students also experienced negative effects such as discomfort, feeling overwhelmed, especially at the beginning of the placement as they began to challenge their own values and beliefs. However, the study noted that these challenges were part of the learning process, and students learned to resolve problems they faced. This reflects that dilemma may trigger learning.

Other barriers can come from limitations of resources and on-time support for students at the communities. For example, in Warren and Sellnow's(2021) study, students experienced frustration due to a lack of support from community partners. Warren and Sellnow (2021) suggested that to improve the effectiveness of SL, community partners need to ensure time to accommodate students' SL participation and involve them in meaningful projects.

From a review of literature on SL, Battistoni(2002, p. 52) outlined common obstacles at different levels of SL implementation. Department and pedagogical barriers include time and resources for implementation, workloads for academics, lack of on-time support from academic leadership and collaboration among stakeholders, lack of reward system, etc. Community partners also face challenges including time, extra work, uncertainty about students' ability and quality of the service, community partners' buy-in, and logistics issues, etc. In short, as noted in prior research, despite some barriers in SL implementation, SL offers significant effects on students and related stakeholders. However, the practices of SL and its effects in HE in Vietnam have not been well researched in the literature.

\section{Promoting Service Learning in Higher Education in Vietnam}

This section presents the relevance of SL in HE, and suggestions for promoting SL in HE in Vietnam. 


\subsection{Relevance of Service Learning in Higher Education in Vietnam}

Over the past decades, HE in Vietnam has achieved significant improvements in educational quality and capacity. However, many HEIs still have to make effort to address such problems as poor connection between theory and practice, students' limited skills, and lack of good partnerships with communities and employers. As noted by World Bank (2009), HE graduates are said to lack necessary skills for good performance in the workplace. Employers reported that despite good theoretical knowledge, graduates often had unsatisfactory practical skills (e.g. practical knowledge of the technology, work experience) and general skills (e.g. teamwork, creative thinking, written and oral communication, communication skills in foreign languages). Due to these skill deficiencies, employers and companies have to retrain, or to provide graduates with more on-the-job training (World Bank, 2009).

There have been significant policy changes and initiatives in HE in Vietnam to resolve the above problems. Within this context, priorities in $\mathrm{HE}$ include improving educational quality and graduate outcomes to respond to workforce needs, enriching pedagogy to provide students with meaningful learning experiences, and promoting linkage between teaching, research, and community service. HEIs also emphasize the aims to ensure a well-rounded development for students, and foster students' citizenship and their abilities for being global citizens in the context of globalization and international integration.

Service learning supports HE visions and missions that emphasize students' civil responsibility, citizenship, critical thinking and commitment to community service (Bringle \& Hatcher, 2000). Regarding its benefits to students and all other stakeholders, as presented previously, SL is a relevant and promising strategy to address current limitations in HE, enhance teaching and learning, and ultimately support HEIs in Vietnam to work toward institutional and national goals.

\subsection{Suggestions for Promoting Service Learning in Higher Education in Vietnam}

In Vietnam, SL has received increasing attention in $\mathrm{HE}$, and has been implemented in a few HEIs such as Hoa Sen University, University of Social Sciences and Humanities of Vietnam National University - Ho Chi Minh City, Can Tho University, as noted in their websites. However, SL has not been widely and systematically implemented in Vietnamese HE. Following are suggestions for promoting the implementation of SL in Vietnam. The suggestions are drawn from the literature (Battistoni, 2001, 2002;
Bringle \& Hatcher, 1996, 2000; Celio et al., 2011; Conway et al., 2009) and adapted to suit the general context of Vietnam.

Service learning is a flexible pedagogy (Bringle \& Hatcher, 1996, 2000) that can be implemented at different levels, e.g. in courses, programs, within or across departments, during short term or long term periods. For any of these types, SL needs to be deliberately and carefully designed (Battistoni, 2001). Particularly, within a department or faculty, it is important that instructors identify and target particular outcomes when planning SL in their courses and curricular, and design SL experiences appropriately (Conway et al., 2009). Instructors also need to identify reflection techniques, and methods for evaluating and measuring outcomes of students' SL participation. It is essential that students are wellprepared and understand about what SL involves.

Moreover, departments and faculties can integrate SL into existing practices of volunteer work, internships, and fieldwork programs. For example, volunteer work mainly focuses on serving the community, so it should be attached to certain relevant courses and given credits to include learning component. Similarly, students' internships and fieldwork should have more focus on reflections and sharing of experiences and values students have gained through their community-based practices.

At a system level, HEIs can consider the following issues for institutionalizing SL. First, SL needs to be included in the institutional strategic development for both short-term and long-term plans (Bringle \& Hatcher, 1996, 2000). Second, institutions need to raise awareness of all stakeholders about the value and relevance of SL in education and establish a shared vision and commitment to provide quality SL to students. Third, there should be an office, center, or unit to manage and support the implementation of SL across the university. Fourth, both administrators and academics need training and professional development on effective planning, implementing, and evaluating SL within departments and across different disciplines. Fifth, as quality SL requires careful planning, time, and effort, the university needs to provide faculties, academics, and students with supportive leadership, adequate resources, and incentives to facilitate and motivate their participation. Sixth, it is important to establish and expand relationships with community partners who are committed to work alongside academics and students during SL programs. Finally, for feasible implementation, SL should be planned and implemented steps by steps, together with reflections and evaluations of its impacts at different levels. Based on analyzing SL impacts, institutions can take actions to improve the quality of SL over time for a sustainable SL institutionalization. 


\section{Conclusions}

Service learning involves a combination of cognitive, affective, and practical aspects which are connected and drawn together through critical reflection (Deeley, 2010, p. 51). The design and implementation of SL at a department or institutional level requires a collective effort and commitment of different stakeholders. There should also be a departmental and institutional strategic plan for promoting and evaluating the effects of SL on student learning as well as on other aspects of HE. Developing a system of SL evaluation, supportive policies and incentives are also necessary for institutionalize SL in Vietnamese HE. The promotion and implementation of SL can be a promising strategy to innovate teaching and learning, improve student outcomes, and support institutional overarching goal to excel in teaching, research, and services in Vietnam. Further studies need to explore an implementation of specific SL activities in HE and impacts of SL experiences in Vietnamese $\mathrm{HE}$ contexts.

\section{References}

[1] Battistoni, R. M. (2001). Service-learning and civic education. Campus Compact Reader, 2, 614.

[2] Battistoni, R. M. (2002). Civic engagement across the curriculum: A resource book for service-learning faculty in all disciplines. Campus Compact.

[3] Bringle, R. G., \& Hatcher, J. A. (1996). Implementing service learning in higher education. Journal of Higher Education, 67(2), 221-239.

[4] Bringle, R. G., \& Hatcher, J. A. (2000). Institutionalization of service learning in higher education. The Journal of Higher Education, 71(3), 273-290.

[5] Carrington, S., Mercer, K. L., Iyer, R., \& Selva, G. (2015). The impact of transformative learning in a critical service-learning program on teacher development: Building a foundation for inclusive teaching. Reflective Practice, 16(1), 61-72.

\section{ISSN 2455-6378}

[6] Caspersz, D., \& Olaru, D. (2015). The value of service-learning: The student perspective. Studies in Higher Education, 1-16.

[7] Celio, C. I., Durlak, J., \& Dymnicki, A. (2011). A meta-analysis of the impact of service-learning on students. Journal of Experiential Education, 34(2), 164-181.

[8] Conway, J., M., Amel, E. L., \& Gerwien, D. P. (2009). Teaching and learning in the social context: A meta-analysis of service-learning's effects on academic, personal, social, and citizenship outcomes. Teaching of Psychology, 36, 233-245.

[9] Creus, A., Fiori, M., \& Gmelch, N. (2019). Expanding the boundaries of service-learning at higher education through e-learning scenarioes: Lessons from teaching innovation projects. Connecting through Educational Technology. Proceedings of the European Distance and ELearning Network 2019 Annual Comference.

[10] Darby, A., \& Newman, G. (2014). Exploring faculty members' motivation and persistence in academic service-learning pedagogy. Journal of Higher Education Outreach and Engagement, 18(2), 91-119.

[11] Deeley, S. J. (2010). Service-learning: Thinking outside the box. Active Learning in Higher Education, 11(1), 43-53.

[12] Fullerton, A., Reitenauer, V. L., \& Kerrigan, S. M. (2015). A grateful recollection: A qualitative study of the long-term impact of service-learning on graduates. Journal of Higher Education Outreach and Engagement, 19(2), 65-92.

[13] Gil-Gómez, J., Chiva-Bartoll, Ó., \& Martí-Puig, M. (2015). The impact of service learning on the training of pre-service teachers: Analysis from a physical education subject. European Physical Education Review, 21(4), 467-484.

[14] Hildenbrand, S., \& Schultz, S. (2015). Implementing service learning in pre-service teacher coursework. Journal of Experiential Learning, 38(3), 262-279.

[15] Warren, J. L., \& Sellnow, D. D. (2021). Increasing learning while serving the community: Student engagement as the key to learning in a basic public speaking course. Journal of Higher Education Outreach and Engagement, 25(1), 25-35.

[16] World Bank. (2009). Vietnam Higher Education and skills for growth. Lao Dong. 